\title{
The effect of aluminum nitride nanoparticles on the structure, phase composition and properties of materials of the Ti-B-Fe system obtained by SHS-extrusion
}

\author{
A. V. Bolotskaia ${ }^{\dagger}$, M. V. Mikheev, P. M. Bazhin, A. M. Stolin \\ †abolotskaia@mail.ru \\ A. G. Merzhanov Institute of Structural Macrokinetics and Materials Science RAS (ISMAN), \\ 8 Academician Osipyan St., Chernogolovka, 142432, Russia
}

The SHS-extrusion method, which combines the combustion processes in the mode of self-propagating high-temperature synthesis (SHS) and the subsequent high temperature shear deformation of the combustion products, was used to obtain metal-ceramic composite materials based on titanium boride with an iron matrix modified by additives of nanoaluminum nitride of grade SHS-Az. It was shown that small additions of nanoscale aluminum nitride powder (3 and 5 wt. \%) to the initial mixture of the Ti-B-Fe system had a significant effect on the temperature and combustion rate of the system: the combustion rate decreased from 16 to $9 \mathrm{~mm} / \mathrm{s}$ and the combustion temperature from $1830-1900^{\circ} \mathrm{C}$ to $1730-1780^{\circ} \mathrm{C}$. The results of $\mathrm{X}$-ray phase analysis showed that the modifying AlN nanopowder decomposed during the SHS process and interacted with titanium and iron matrix forming additional phases of $\mathrm{TiN}$ and $\mathrm{AlFe}_{3}$. This is the main cause of the reduction of the temperature and combustion rate during synthesis. A refinement of the grains of titanium diboride in the modified samples from $0.5-2.5 \mu \mathrm{m}$ to $0.1-1.5 \mu \mathrm{m}$ was observed using a scanning electron microscope. Microhardness measurements showed that the obtained compact metal-ceramic materials modified with the nanoscale AlN powder had $10 \%$ higher microhardness values compared to samples without additives.

Keywords: cermet composite material, SHS-extrusion, nanopowder, SHS-Az, modification.

УДК: 544-971.2, 66.017, 66-963

\section{Влияние наночастиц нитрида алюминия на структуру, фазовый состав и свойства материалов системы Ti-B-Fe, полученных методом СВС-экструзии}

\author{
Болоцкая А. В. ${ }^{\dagger}$, Михеев М. В., Бажин П. М., Столин А.М. \\ Институт структурной макрокинетики и проблем материаловедения им. А. Г. Мержанова РАН (ИСМАН), \\ ул. Академика Осипьяна, 8, Черноголовка, 142432, Россия
}

Методом СВС-экструзии, который сочетает процессы горения в режиме самораспространяющегося высокотемпературного синтеза и последующее высокотемпературное сдвиговое деформирование продуктов горения, были получены металлокерамические композиционные материалы на основе боридов титана с железной матрицей, модифицированные добавками наноразмерного порошка нитрида алюминия марки СВС-Аз. Показано, что малые добавки нанопорошка нитрида алюминия (3 и 5 мас.\%) в исходную шихту системы Тi-B-Fе оказывают значительное влияние на температуру и скорость горения изучаемой системы: скорость горения снижается с 16 до 9 мм/с, а температура горения - с $1830-1900^{\circ} \mathrm{C}$ до $1730-1780^{\circ} \mathrm{C}$. Из данных рентгенофазового анализа установлено, что модифицирующий нанопорошок AlN разлагается в ходе проведения CBC-процесса. Это является причиной снижения температуры и скорости горения. Происходит химическое взаимодействие продуктов разложения с титаном и железной матрицей с образованием дополнительных фаз TiN и $\mathrm{AlFe}_{3}$. Результаты сканирующей электронной микроскопии показали измельчение зерен основной фазы диборида титана в модифицированных 
образцах с 0.5-2.5 мкм до 0.1-1.5 мкм. Эти изменения, в свою очередь, отразились на микротвердости образцов. Измерение микротвердости свидетельствует о том, что полученные компактные металлокерамические материалы, модифицированные наноразмерным порошком AlN, обладают в среднем на 10\% более высокими показателями микротвёрдости по сравнению с образцами, полученными без использования наноразмерных добавок.

Ключевые слова: металлокерамический композиционный материал, СВС-экструзия, нанопорошок, СВС-Аз, модифицирование.

\section{1. Введение}

В настоящее время в области упрочняющих технологий перспективным направлением является изготовление жаропрочных, износостойких материалов и покрытий. Современную промышленность невозможно представить без металлокерамических композиционных материалов (МКМ). Повышение эксплуатационных свойств деталей машин, подвергающихся интенсивному износу, является одной из важнейших задач материаловедения [1-4]. Для повышения эксплуатационных свойств путем нанесения защитных покрытий перспективным считается метод электроискрового легирования (ЭИЛ). Эффективность метода ЭИЛ определяется качеством применяемых электродных МКМ. Такие материалы должны обеспечивать стабильность процесса нанесения покрытия, а также высокий уровень физико-механических и эксплуатационных свойств поверхности.

К перспективным МКМ относятся материалы на основе боридов титана, которые являются износостойкими, сверхтвердыми материалами, имеющими низкий коэффициент термического расширения. Однако применение таких материалов в чистом виде ограничено высокой эрозионной стойкостью данных материалов, что в свою очередь накладывает ограничение на толщину и качество получаемого покрытия [5]. Для снижения хрупкости соединения материала покрытия и подложки целесообразно введение металлической связки, которая будет смачивать твердую износостойкую фазу. В таком случае металлическая связка будет обволакивать частицы износостойкой фазы, что обеспечит качественное сцепление с легируемой поверхностью. Помимо этого, металлическая связка должна обладать хорошей химической устойчивостью, а также обладать близким коэффициентом термического расширения c износостойкой составляющей. Для материалов на основе боридов титана железная металлическая связка удовлетворяет перечисленным требованиям. Сочетание данных свойств делает материалы на основе боридов титана с железной матрицей наиболее перспективными при их дальнейшем применении в качестве электродов для нанесения защитных покрытий методами электроискрового легирования и электродуговой наплавки [6-8].

Материалы на основе боридов титана в основном получают карботермическим и магниетермическим методом или искровым плазменным спеканием. Недостаток данных методов кроется в организации сложного многостадийного технологического цикла, который осуществляется в агрегатах с низкой производительностью [9]. Для получения изучаемых МКМ перспективной считается технология самораспространяющегося высокотемпературного синтеза (CBC). Этот метод является энергоемким и простым в технологическом плане. Получаемые по данной технологии материалы характеризуется высокой чистотой конечных продуктов синтеза и высокими скоростями производства [10].

Получение с минимальной пористостью МКМ на основе боридов титана реализуется методом СВСэкструзии, благодаря сочетанию процессов горения и высокотемпературного сдвигового деформирования. Полученные этим методом компактные МКМ обладают низкой пористостью не более $1-5 \%$ [11,12]. Ранее был проведен ряд работ по получению компактных длинномерных материалов на основе системы TiB/Ti при их модифицировании наноразмерными порошками AlN марки СBC-Аз [13]. Полученные МКМ, обладают более высокими показателями микротвёрдости по сравнению с образцами, полученными без использования наномодифицирующих добавок. Данное повышение микротвёрдости связанно с уменьшением размера зерна основной фазы и образованием более твердых фаз.

Целью данного исследования является получение методом СВС-экструзии электродных МКМ на основе Ti-B с железной матрицей, модифицированных наноразмерным порошком AlN марки CBC-Аз, а также изучение структуры и свойств полученных материалов.

\section{2. Методы исследований}

В качестве объектов исследования были выбраны стехиометрические смеси, составы и исходные характеристики порошков представлены в Табл. 1.

Модифицирующие добавки наноразмерного $\mathrm{AlN}$ были получены в СамГТУ по азидной технологии самораспространяющегося высокотемпературного синтеза. Данная технология позволяет получать микрои нанопорошки нитридов, карбидов и композиций на их основе $[14,15]$.

Предварительно просушенные при $80^{\circ} \mathrm{C}$ порошки дозировались согласно данным Табл. 1 на весах CAS MWP-300, обеспечивающих точность измерения не ниже $0.1 \%$. Смешение шихты проводилось в шаровых мельницах, при соотношении массы шихты и массы размольных шаров 1:3.5 при комнатной температуре и атмосферном давлении в течение 4 ч, при частоте вращения барабана 0.56 об/с. После снятия шихта просеивалась через сито в контейнер и помещалась в сушильный шкаф для удаления остаточной 
влаги в течение 12 ч. Далее из порошковой смеси на гидравлическом прессе изготавливались шихтовые заготовки, которые обертывались слоем асбестовой ткани толщиной 2 мм.

Расчет адиабатической температуры горения производился с помощью программы «Thermo». Экспериментальные измерения характеристик горения осуществлялись на установке термопарных измерений, моделирующей условия протекания процесса при СВС-экструзии. После инициирования горения с неизолированного торца заготовки вольфрамовой спиралью, возникает фронт горения, который проходит через погруженные в образец на фиксированном расстоянии вольфрам-рениевые термопары (ВР5-ВР20, $d=200$ мкм). После прохождения фронта горения через термопару сигнал шел на 16 канальную АЦП LTR-U1, a затем, после обработки, результаты измерения выдавались в виде температурных профилей горения.

Метод СВС-экструзии заключается в проведении синтеза материала в режиме горения с последующим высокотемпературным сдвиговым деформированием и экструдированием продуктов синтеза через формообразующую матрицу с диаметром выходного отверстия 5 мм и углом конусной части $120^{\circ}$. Для преодоления эффекта «разбухания струи» [16] и лучшего обжатия материала на выходе из формующего отверстия матрицы выдавливание проводилось в кварцевый калибр диаметром 5 мм.

Исследования полученных образцов проводились на оборудовании распределительного центра коллективного пользования ИСМАН. Фазовый состав продуктов синтеза определялся методом рентгенофазового анализа (РФА) на дифрактометре ДРОН-3М на излучении $\mathrm{Cu}$. Анализ микроструктуры проводился на сканирующем электронном микроскопе LEO 1450 VP Carl Zeiss. Измерение микротвердости полученных образцов проводилось на приборе ПМТ-3 согласно ГОСТ 9450-76 при нагрузке 100 г (проводили 8 измерений).

\section{3. Результаты и их обсуждение}

Результаты адиабатических расчетов и термопарных измерений характеристик горения изучаемых составов представлены в Табл. 2.

Результаты показывают, что при добавлении 3 мас.\% наноразмерного нитрида алюминия в исходную шихту скорость горения снижается с 16 до 13 мм/с, при этом температура горения снижается с 1830-1900 до $1760-1840^{\circ} \mathrm{C}$. При добавлении в исходную шихту 5 мас.\% нитрида алюминия скорость горения снижается до $9 \mathrm{~mm} / \mathrm{c}$, а температура горения понижается до $1730-1780^{\circ} \mathrm{C}$. Такое снижение характеристик горения исследуемых составов обусловлено тем, что теплота, выделяемая при химическом взаимодействии титана с бором, частично расходуется на термическое разложение нитрида алюминия и дальнейшее низкоэкзотермическое или эндотермическое взаимодействие с продуктами горения. Результаты расчета адиабатических температур горения образцов коррелируют с экспериментальными данными, показывая снижение температуры с 2225 до $2135^{\circ} \mathrm{C}$ при добавлении 3 мас.\% нитрида алюминия и до $2050^{\circ} \mathrm{C}$ при добавлении 5 мас.\%.

После проведения серии экспериментов и оптимизации технологических режимов СВС-экструзии исследуемых составов были получены опытные образцы компактных стержней. Максимальные длины полученных образцов без добавок, с 3 и 5 с мас.\% AlN составляли соответственно 265, 240 и 270 мм.

На Рис. 1а представлена микроструктура шлифа поперечного сечения полученного образца. Микроструктура материала системы Ti-B-Fe без добавок нитрида алюминия (Рис. 1a) представляет из себя равномерное распределение зерен, преимущественно прямоугольной формы, диборида титана (темные области) в матрице железа (светлые области). Размер зерен диборида титана варьируется от 0.5 до 2.5 мкм. Так же в структуре наблюдаются включения округлой

Табл. 1. Характеристики исходных порошковых компонентов.

Table 1. Characteristics of initial powder components.

\begin{tabular}{|c|c|c|c|c|}
\hline $\begin{array}{c}\text { Компонент } \\
\text { Component }\end{array}$ & $\begin{array}{c}\text { Mac.\% } \\
\text { Wt.\% }\end{array}$ & $\begin{array}{c}\text { Марка порошка } \\
\text { Powder grade }\end{array}$ & $\begin{array}{c}\text { Содержание основного вещества } \\
\text { не менее, мас.\% } \\
\text { Content of the main substance no less, wt.\% }\end{array}$ & $\begin{array}{c}\text { Размер частиц основной } \\
\text { фракции, мкм } \\
\text { Particle size of the main fraction, } \mu \mathrm{m}\end{array}$ \\
\hline $\mathrm{Ti}$ & 57 & ПТОМ-1/PTOM-1 & 98.8 & 45 \\
\hline $\mathrm{B}$ & 13 & Б-99A/B-99A & 99.5 & 20 \\
\hline $\mathrm{Fe}$ & 30 & Р-10/R-10 & 97 & $0.08-0.1$ \\
\hline $\mathrm{AlN}$ & $3 ; 5$ & СВС-Аз/SHS-Az & 97 & 25 \\
\hline
\end{tabular}

Табл. 2. Характеристики горения исследуемых составов.

Table 2. Combustion characteristics of the studied compounds.

\begin{tabular}{|c|c|c|c|c|}
\hline $\begin{array}{c}\text { Состав } \\
\text { Composition }\end{array}$ & $\begin{array}{c}\text { Относительная } \\
\text { плотность заготовки } \\
\text { Relative density of the } \\
\text { preform }\end{array}$ & $\begin{array}{c}\text { Температура, }{ }^{\circ} \mathrm{C} \\
\text { Temperature, }{ }^{\circ} \mathrm{C}\end{array}$ & $\begin{array}{c}\text { Адиабатическая } \\
\text { температура, }{ }^{\circ} \mathrm{C} \\
\text { Adiabatic temperature, }{ }^{\circ} \mathrm{C}\end{array}$ & $\begin{array}{c}\text { Скорость горения, } \\
\text { мurning rate, mm/s }\end{array}$ \\
\hline $0.57 \mathrm{Ti}-0.13 \mathrm{~B}-0.3 \mathrm{Fe}$ & 0.6 & $1830-1900$ & 225 & 16 \\
\hline $0.57 \mathrm{Ti}-0.13 \mathrm{~B}-0.3 \mathrm{Fe}+3$ мac.\% AlN & 0.6 & $1760-1840$ & 2135 & 13 \\
\hline $0.57 \mathrm{Ti}-0.13 \mathrm{~B}-0.3 \mathrm{Fe}+5$ мac.\% AlN & 0.6 & $1730-1780$ & 2050 & 9 \\
\hline
\end{tabular}


формы серого цвета. Как показали результаты анализа элементного состава данные включения являются нитридом титана, с размером зерна от 0.5 до 2 мкм. Материал содержит 5 фаз (Рис. 1b). Основной фазой является $\mathrm{TiB}_{2}$, равномерно распределенный в $\mathrm{Fe}$-матрице. Дополнительно образуются TiFe и твердый раствор бора в железе, а также остается небольшое количество свободного титана. Общее количество нитрида титана не превышает 5 мас.\%.

На Рис. 2 а представлены результаты СЭМ образцов содержащих 3 мас.\% AlN. B микроструктуре образца с добавками 3 мас.\% AlN, в отличие от образца без добавок, размер зерен диборида титана ниже и варьируется в пределах от 0.1 до 2 мкм. Введение AlN в исходную шихту приводит к увеличению размера зёрен TiN до 3 мкм. Как показали результаты РФА (Рис. 2b) добавление 3 мас.\% AlN приводит к увеличению количества фазы нитрида титана. Фазовый состав материала состоит из 7 фаз: $\mathrm{TiB}_{2}$ распределенного в Fe-матрице; интерметаллидов: $\mathrm{AlFe}_{3}, \mathrm{Fe}_{2} \mathrm{Ti}$; твердых растворов $\mathrm{Fe}_{3} \mathrm{Ti}_{3} \mathrm{~B}, \mathrm{Fe}_{2} \mathrm{~B}$ и включений TiN. Это указывает на то, что при СВС нанопорошок нитрида алюминия разлагается с дальнейшим химическим взаимодействием с продуктами горения.

На Рис. 3 а показана микроструктура образца c 5 мас.\% AlN. Увеличение количества AlN до 5 мас.\% приводит к измельчению зерен основной фазы диборида титана, размеры которых лежат в интервале от 0.1 до 1.5 мкм, а также к еще большему увеличению содержания нитрида титана, что подтверждается результатами РФА (Рис. 3 b). Фазовый состав материала с добавками 5 мас.\% AlN практически совпадает с фазовым составом материала содержащего 3 мас.\% $\mathrm{AlN}$ и состоит из 6 фаз: $\mathrm{TiB}_{2}$ распределенного в Fе-матрице;
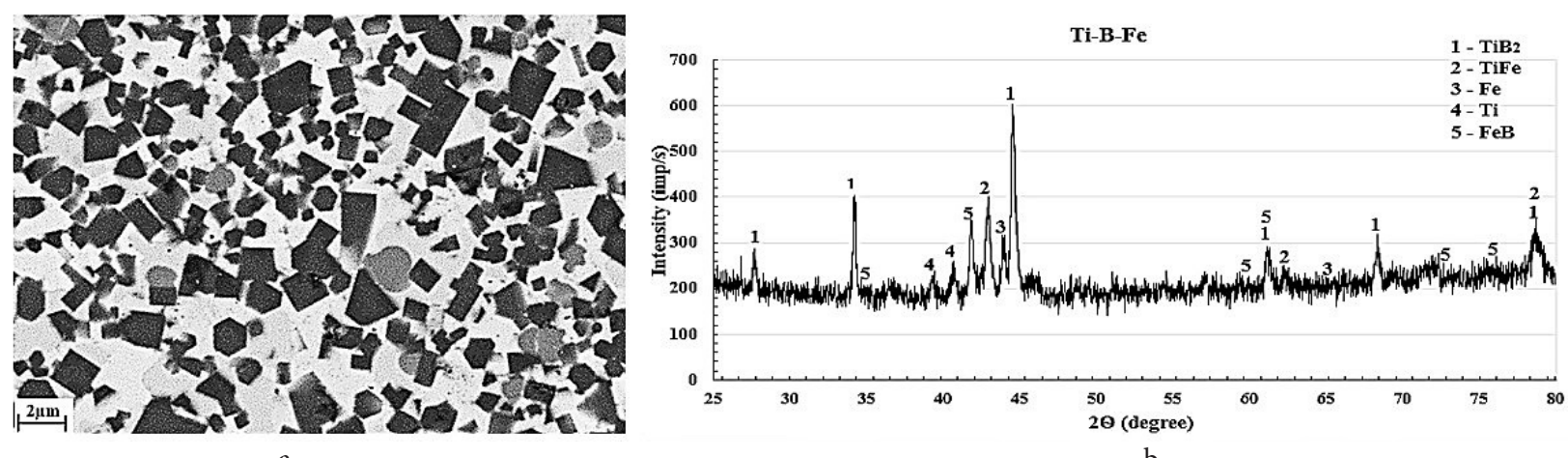

a

Рис. 1. Микроструктура материала без AlN (a), дифрактограмма материала без AlN (b).

Fig. 1. Microstructure of the material without additive (a), X-ray diffraction pattern without additives (b).

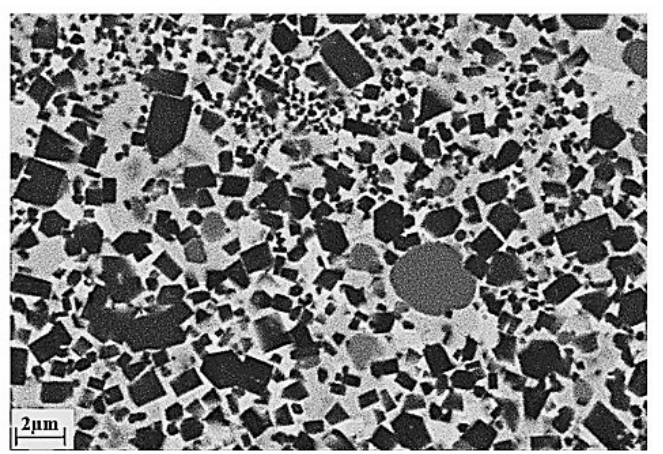

a

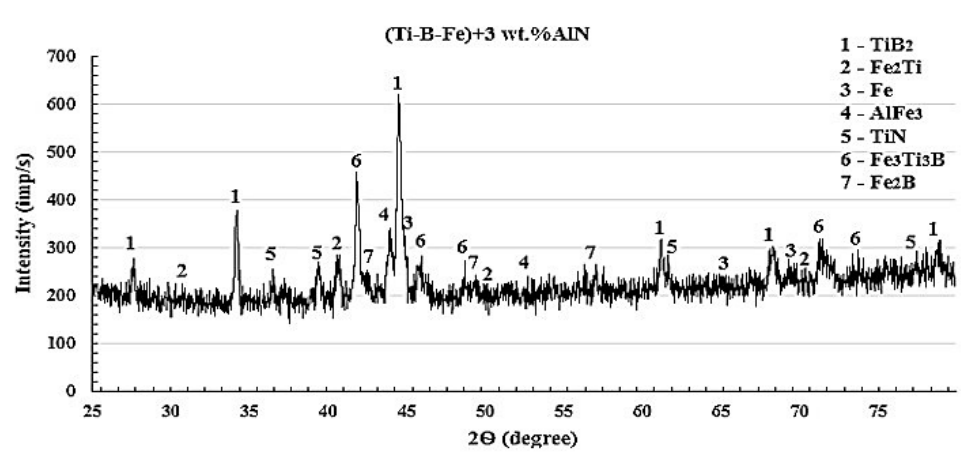

$\mathrm{b}$

Pис. 2. Микроструктура материала с 3 мac.\% AlN (a), дифрактограмма материала с 3 мac.\% AlN (b).

Fig. 2. Microstructure of the material with 3 wt.\% AlN (a), X-ray diffraction pattern with 3 wt.\% AlN (b).

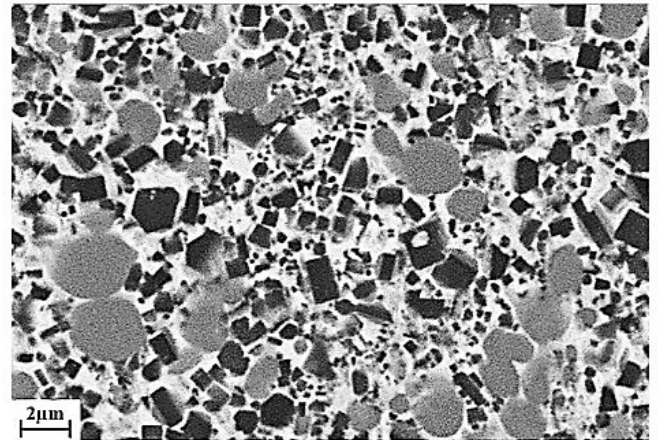

a

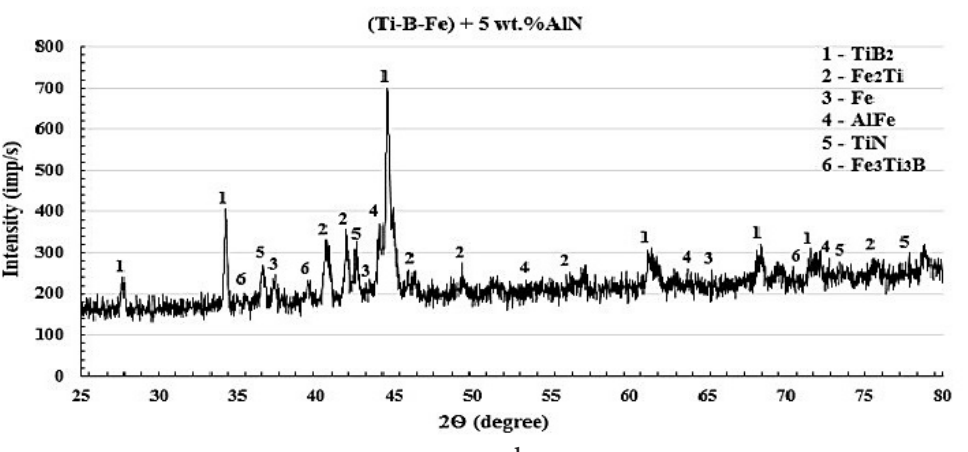

b

Рис. 3. Микроструктура материала с 5 мас.\% $\operatorname{AlN}($ a), дифрактограмма материала с 5 мac.\% $\operatorname{AlN}$ (b).

Fig. 3. Microstructure of the material with $5 \mathrm{wt} . \%$ AlN (a), X-ray diffraction pattern with 5 wt.\% AlN (b). 
Табл. 3. Микротвердость полученных образцов.

Table 3. Microhardness of the samples.

\begin{tabular}{|c|c|c|c|}
\hline \multicolumn{3}{|c|}{ Микротвердость, кГ/мм² / Microhardness, kgf/mm $\mathrm{mm}^{2}$} \\
\hline No. & $0.57 \mathrm{Ti}-0.13 \mathrm{~B}-0.3 \mathrm{Fe}$ & $\begin{array}{c}0.57 \mathrm{Ti}-0.13 \mathrm{~B}-0.3 \mathrm{Fe}+3 \mathrm{mac} \% \mathrm{AlN} \\
0.57 \mathrm{Ti}-0.13 \mathrm{~B}-0.3 \mathrm{Fe}+3 \mathrm{wt} \% \text { AlN }\end{array}$ & $\begin{array}{c}0.57 \mathrm{Ti}-0.13 \mathrm{~B}-0.3 \mathrm{Fe}+5 \mathrm{mac} . \% \mathrm{AlN} \\
0.57 \mathrm{Ti}-0.13 \mathrm{~B}-0.3 \mathrm{Fe}+5 \mathrm{wt} . \% \mathrm{AlN}\end{array}$ \\
\hline 1 & 974 & 1426 & 1226 \\
\hline 2 & 1168 & 1114 & 1426 \\
\hline 3 & 1226 & 1354 & 1114 \\
\hline 4 & 1114 & 1426 & 1426 \\
\hline 5 & 1168 & 1288 & 1354 \\
\hline 6 & 1226 & 1426 & 1114 \\
\hline 7 & 1288 & 1288 & 1288 \\
\hline 8 & 1226 & 1114 & \\
\hline
\end{tabular}

двух интерметаллидов: $\mathrm{AlFe}_{3}, \mathrm{Fe}_{2} \mathrm{Ti}$; твердых растворов $\mathrm{Fe}_{3} \mathrm{Ti}_{3} \mathrm{~B}$ и включений TiN.

В Табл. 3 представлены результаты измерений микротвердости полученных материалов. Максимальное значение микротвёрдости образцов Ti-B-Fe составила

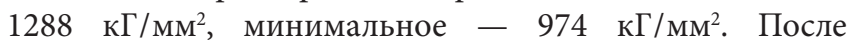
добавления 3 и 5 мас.\% AlN максимальное значение микротвердости материала составило 1426 кГ/ м $^{2}$,

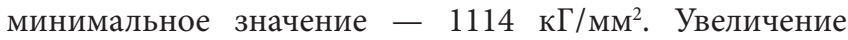
микротвердости материала связанно с измельчением зерна диборида титана, а также с образованием большего количества нитрида титана. Полученные данные свидетельствуют о повышении микротвердости экструдированных образцов в среднем на $10 \%$.

\section{4. Выводы}

1. Методом СВС-эктрузии получены компактные стержни из материалов системы (Ti-B-Fe)+3(5) мac.\% AlN. Установлено, что в условиях сдвигового деформирования при CBC-экструзии модифицирование Ti-B-Fe малыми добавками наноразмерного порошка нитрида алюминия приводит к измельчению зеренной структуры материала. Добавление 3 и 5 мас.\% AlN приводит к повышению микротвердости экструдированных образцов в среднем на $10 \%$.

2. Основная фаза $\mathrm{TiB}_{2}$ равномерно распределена в поперечном сечении образца.

3. Добавление 3 и 5 мас.\% AlN снижает температуру с $1830-1900^{\circ} \mathrm{C}$ до $1730-1780^{\circ} \mathrm{C}$ и скорость горения с 16 до 9 мм/с. Снижение данных показателей обусловлено тем, что при горении часть тепла от химической реакции расходуется на разложение AlN.

4. Увеличение содержания AlN приводит к образованию новых фаз: интерметаллидов $\mathrm{AlFe}_{3}, \mathrm{Fe}_{2} \mathrm{Ti}$, твердых растворов $\mathrm{Fe}_{3} \mathrm{Ti}_{3} \mathrm{~B}, \mathrm{Fe}_{2} \mathrm{~B}$ и TiN.

\section{Литература/References}

1. T.W. Clyne. An introduction to composite materials. Cambridge university press (2019) 345 p. Crossref

2. C.T. Lynch, J.P. Kershaw. Metal Matrix Composites. Boca Raton, CRC Press (2018) 180 p. Crossref

3. T.A. Restivo, R.F. Beccari. Journal of the European Ceramic Society. 39 (3), 552 (2019). Crossref
4. S. V. Zhitnuyk. Proceedings of VIAM. 8 (68), 81 (2018). (in Russian) [C.В. Житнюк. Труды ВИАМ. 8 (68), 81 (2018). Crossref

5. A.P. Umanskiy. Aerospace Engineering and Technology. 9 (96), 214 (2012). (in Russian) [А.П. Уманский. Авиационнокосмическая техника и технология. 9 (96), 214 (2012).]

6. K.A. Kolesnikova. Kompozitsionnyye iznosostoykiye pokrytiya sistemy Ti-B-Fe, poluchennyye metodom elektronno-luchevoy naplavki $\mathrm{V}$ vakuume: abstract of dissertation. Tomsk (2008) 18 p. (in Russian) [К.А. Колесникова. Композиционные износостойкие покрытия системы Ti-B-Fe, полученные методом электронно-лучевой наплавки в вакууме: автореферат диссертации. Томск (2008) 18 с.]

7. M. Selvakumar, T. Ramkumar, P. Chandrasekar. Journal of Thermal Analysis and Calorimetry. 136 (1), 419 (2019). Crossref

8. S.G. Grigorenko, G. M. Grigorenko, O.M. Zadorozhnyuk. Sovremennaya Elektrometallurgiya. 3,51 (2017).(in Russian) [С.Г. Григоренко, Г.М. Григоренко, О.М. Задорожнюк. Современная электрометаллургия. 3, 51 (2017).] Crossref

9. V. Moradi. Ceramics International. 44 (16), 19421 (2018). Crossref

10. A.G. Merzhanov. Kontseptsiya razvitiya samorasprostranyayushchegosya vysokotemperaturnogo sinteza kak oblasti nauchno-tekhnicheskogo progressa. Chernogolovka, Territoria (2003) 263 p. (in Russian) [А.Г. Мержанов. Концепция развития самораспространяющегося высокотемпературного синтеза как области научно-технического прогресса. Черноголовка, Территория (2003) 263 с.]

11. A.S. Konstantinov. Composites Part A: Applied Science and Manufacturing. 108, 79 (2018). $\underline{\text { Crossref }}$

12. P. M. Bazhin. Materials. 9 (12), 1027 (2016). Crossref

13. A. V. Bolotskaia. Perspective materials. 1, 73 (2019). (in Russian) [А. В. Болоцкая. Перспективные материалы. 1, 73 (2019).] Crossref

14. Yu. V. Titova, D.A. Maydan. Sovremennyye materialy, tekhnika i tekhnologii. 6(14), 133 (2017). (in Russian) [Ю. В. Титова, Д. А. Майдан. Современные материалы, техника и технологии. 6(14), 133 (2017).]

15. A. P. Amosov. Russian Journal of Inorganic Chemistry. 31 (10), 1225 (2016). $\underline{\text { Crossref }}$

16. A.P. Chizhikov. Doklady Chemistry. 484 (2), 79 (2019). $\underline{\text { Crossref }}$ 